\title{
EMPRENDEDORES Y CAPITAL RIESGO EN ESPAÑA: EL CASO DE FOND-ICO GLOBAL
}

\author{
Autores: Susana de los Ríos Sastre \\ Departamento de Gestión Financiera \\ Facultad de Ciencias Económicas y Empresariales \\ Universidad Pontificia Comillas \\ Isabel Rodríguez García ${ }^{2}$ \\ Socia responsable de Private Equity \\ King \& Wood Mallesons \\ Rocío Sáenz-Díez Rojas ${ }^{3}$ \\ Departamento de Gestión Financiera \\ Facultad de Ciencias Económicas y Empresariales \\ Universidad Pontificia Comillas
}

\footnotetext{
${ }^{1}$ srios@icade.comillas.edu

${ }^{2}$ isabel.rodriguez@eu.kwm.com

${ }_{3}^{3}$ rsaenz@icade.comillas.edu
} 


\title{
Resumen
}

En este trabajo se revisan las bondades del capital riesgo como fuente alternativa de financiación empresarial, especialmente para empresas que se hallan en las primeras fases de desarrollo. Asimismo, se expone cómo el ecosistema emprendedor es importante a la hora de generar innovación y reactivar la economía. Teniendo en cuenta la importancia que el sector público tiene en el estímulo de la actividad emprendedora y en el fomento del capital riesgo como forma de financiación, en este artículo se analizan los factores de éxito de las iniciativas públicas y el reciente programa español Fond-ICO Global.

Palabras clave: capital riesgo; emprendedor; financiación; iniciativas públicas; Fond-ICO Global

\section{Entrepreneurs and venture capital in Spain: The Fond-ICO Global pro- gram}

\begin{abstract}
Venture capital investments are an important source of funds particularly useful for start-ups and companies at a very young stage of their life. It is therefore necessary to promote venture capital activity as well as entrepreneurship to boost innovation and economic growth. The public sector role is important in stimulating these activities. We analyze the main policy levers consistent with achieving this objective successfully, and check if the Spanish public program Fond-ICO Global follows them.
\end{abstract}

Key words: venture capital; entrepreneurs; financing; public policy; Fond-ICO Global

\section{INTRODUCCIÓN}

En la actualidad, Europa se enfrenta a nuevos retos como consecuencia del estancamiento en el crecimiento económico y de las difíciles condiciones sociales aparejadas al mismo, y las autoridades luchan continuamente para impulsar la actividad económica en la zona. Para lograr una reactivación de dicha actividad es preciso, por una parte, mejorar las ayudas a las pequeñas y medianas em- 
presas (PYME) $)^{4}$, que son el principal agente productivo de la economía europea, y por otra, impulsar la creación de empresas nuevas fomentando la actividad emprendedora.

Diversos estudios han vinculado el papel de los emprendedores, y de su mano la industria de capital riesgo, con una mayor innovación, que a su vez puede ser un importante estímulo para el crecimiento económico. En general, un ecosistema emprendedor sano unido a una industria de capital riesgo activa, puede realizar importantes contribuciones en una economía orientada a la innovación. Y, en este sentido, la participación del sector público dirigida a promover un ecosistema emprendedor dinámico se justifica plenamente.

La intervención institucional para propiciar y favorecer la actividad del sector de capital riesgo, puede llevarse a cabo por medio de la participación directa del sector público en programas que invierten en empresas o en fondos de capital riesgo, o bien de una forma indirecta, tratando de desarrollar un entorno empresarial apropiado. No obstante, la participación pública en este ámbito ha de realizarse con cautela, ya que no siempre estas iniciativas acaban siendo exitosas y produciendo el efecto deseado.

En este trabajo se analiza, en concreto, una de las iniciativas públicas españolas más recientes, como es el fondo de fondos Fond-ICO Global. Se trata de un programa lanzado por el Instituto del Crédito Oficial (ICO) en 2013 para estimular la financiación no bancaria de las empresas españolas por medio de la creación de fondos de capital riesgo. El objetivo principal del análisis es comprobar si Fond-ICO Global se adecúa a las directrices marcadas en la doctrina como medidas recomendadas para lograr la efectividad de las iniciativas públicas en el ámbito del capital riesgo.

El presente artículo se ha estructurado en tres bloques: en primer lugar, se revisa la importancia del capital riesgo como fuente de financiación para la actividad emprendedora y, por tanto, su potencial como impulsor del crecimiento económico; en segundo lugar, se expone la relevancia del papel del sector público en el estímulo del capital riesgo dentro del denominado ecosistema emprendedor, bien sea a través de medidas de intervención indirectas o directas, haciendo mención expresa en estas últimas al caso español; y en tercer lugar, se examina si Fond-ICO Global, como iniciativa pública directa, cumple con las recomendaciones para que un programa público sea efectivo y logre sus objetivos con éxito. En el último apartado se presentan, a modo de resumen, las principales conclusiones obtenidas del trabajo realizado.

\footnotetext{
${ }^{4}$ Recordemos que en el entorno de la Unión Europea el término PYME incluye microempresas, pequeñas y medianas empresas. En concreto, se consideran medianas aquellas empresas con un número de empleados inferior a 250, cuyo volumen de negocios anual no exceda de 50 millones de euros o con un balance general anual inferior a 43 millones de euros, mientras que las pequeñas ocupan a menos de 50 empleados y un volumen de negocios o un balance general anual que inferior a 10 millones de euros y, por último, se califican como microempresas las que tienen menos de 10 empleados y un volumen de negocios o un balance general anual que no supere los 2 millones de euros.
} 


\section{EL CAPITAL RIESGO, LOS EMPRENDEDORES Y EL CRECIMIENTO ECONÓMICO}

\subsection{La financiación de PYME y emprendedores: el papel del capital riesgo}

La actividad empresarial de los denominados emprendedores, es decir, empresarios que acometen la labor de crear empresas canalizando a través de la iniciativa privada nuevas ideas y prácticas de negocio, se encuentra actualmente en el centro de atención de las autoridades económicas y de la sociedad en su conjunto.

Según los datos más recientes disponibles, en 2013, 99 de cada 100 negocios en Europa eran pequeñas y medianas empresas, a las que correspondían 2 de cada 3 empleados y el 58\% del valor añadido producido en ese periodo (Comisión Europea, 2014). Aunque estos datos confirman la importancia de la PYME en la economía europea, el interés relativamente reciente hacia la actividad de empresas jóvenes y emprendedores innovadores se debe también al impacto en la vida empresarial de los cambios tecnológicos y a las actuales circunstancias económicas.

La revolución tecnológica ha cambiado los fundamentos de la economía de mercado de las últimas décadas, eliminando viejos negocios, haciendo desaparecer intermediarios e ineficiencias y acelerando el ritmo de la innovación, de forma que las empresas más valiosas son las más flexibles, eficientes y capaces de adaptarse. Al mismo tiempo, la tecnología permite un intercambio de ideas, internacionalización y colaboración entre agentes económicos y sociales de forma rápida y casi gratuita como no había ocurrido antes, permitiendo a los agentes más innovadores y creativos la puesta en marcha de sus ideas de una forma más sencilla de lo que hubiera sido posible anteriormente.

El protagonismo de estos nuevos emprendedores es aún mayor si se analiza a la luz de la crisis económica de los últimos años, puesto que nadie pone en duda que la innovación llevada a cabo por emprendedores y empresas nuevas de reciente creación impulsan el tan necesario crecimiento económico.

En palabras de Calleja Crespo (2013), actual Director General de Empresa e Industria de la Comisión Europea, los emprendedores "son la savia revitalizadora de la economía europea: cada año las nuevas empresas, además de ser la principal vía de incorporación de nuevos productos y tecnologías al mercado, son responsables de la creación de más de 4 millones de nuevos puestos de trabajo. Una economía europea saludable, dinámica y con perspectivas de futuro no es comprensible si no existe un flujo ininterrumpido de emprendedores en su base".

Mientras que Europa se va recuperando lentamente de la crisis financiera, en general, las empresas europeas continúan teniendo dificultades para conseguir financiación. Esta situación es aún más complicada para las empresas de menor tamaño que, como ya se ha mencionado, forman el grueso del tejido empresarial 
europeo. Por otra parte, en la actualidad, la financiación bancaria se mantiene como una de las principales fuentes de recursos para las empresas europeas ${ }^{5}$, aunque en la medida en que el sistema bancario europeo está en proceso de desapalancamiento, el acceso al crédito bancario sigue siendo muy limitado para la mayoría de las empresas ${ }^{6}$. Desde varias instancias nacionales e internacionales se está intentando impulsar el acceso a otras alternativas de financiación para las empresas, conscientes de la importancia que este aspecto tiene para la recuperación económica de Europa?

Las iniciativas emprendedoras y empresas de reciente creación son las que tienen mayores problemas para obtener financiación tradicional, tanto bancaria como a través de los mercados de capitales (renta fija o acciones), debido a su perfil de riesgo y a las asimetrías informativas inherentes al mercado. En este contexto, el capital riesgo puede ser una buena alternativa para conseguir fondos a largo plazo.

Las formas de financiación más habituales para empresas de reciente creación son, junto con el capital riesgo, la inversión directa de individuos (conocidos habitualmente como "business angels") o la inversión empresarial por parte de socios industriales más establecidos ${ }^{8}$. Cabría también mencionar el reciente fenómeno de las plataformas de financiación participativa conocido como crowdfunding o crowdlending y su papel a la hora de proporcionar fondos a iniciativas emprendedoras 9 . Este trabajo va a centrarse en la actividad de capital riesgo.

A modo de mera introducción se exponen a continuación los conceptos básicos que caracterizan esta actividad.

Se entiende como capital riesgo los fondos gestionados de forma profesional e independiente y dedicados a invertir de forma temporal (medio-largo plazo) en

\footnotetext{
${ }^{5}$ El Director General de Negocios del ICO en una reciente entrevista mencionaba que, mientras que en Estados Unidos las empresas en su conjunto pueden obtener hasta un $80 \%$ de su financiación de fuentes diferentes a la bancaria (mercados de deuda e instrumentos de capital), las empresas españolas obtienen menos de un 20\% de su financiación de dichas fuentes (Gefaell, 2014).

${ }^{6}$ Véase ECB (2014) y OCDE (2013).

${ }^{7}$ Sirva como ejemplo el recientemente aprobado (17 de octubre de 2014) Proyecto de Ley de fomento de la financiación empresarial. Y, a nivel internacional, el workshop organizado por el Banco Europeo de Inversiones (BEI) y Fondo Monetario Internacional (FMI) a finales de octubre de 2014 bajo el título "Unlocking SME Financing in Europe and the Role of Capital Markets", en el cual se puso de manifiesto una vez más que un mayor acceso a la financiación para la PYME es vital para para mejorar el crecimiento y el empleo en Europa y así conseguir una verdadera recuperación económica. Para más detalle sobre este evento pueden consultarse: http://www.eib.org/infocentre/events/all/unlocking-smefinancing-in-europe.htm

${ }^{8}$ Véase Park y Steensma (2012) y Dushnitsky y Shapira (2010) sobre la actividad de Corporate Venture Capital, entendiendo como tal unidades dentro de empresas industriales que se dedican a la búsqueda e inversión en proyectos de empresas jóvenes y de alto crecimiento, y su comparación con la actividad habitual de inversores independientes de capital riesgo.

${ }^{9}$ Véase el mencionado Proyecto de Ley de fomento de la financiación empresarial.
} 
los recursos propios (o en activos financieros ligados a dichos recursos propios) de empresas no cotizadas y de alto crecimiento. En el preámbulo de la recientemente aprobada Ley 22/2014 10 se define el capital riesgo como "aquellas estrategias de inversión que canalizan financiación de forma directa o indirecta a empresas, maximizan el valor de la empresa generando gestión y asesoramiento profesional, y desinvierten en la misma con el objetivo de aportar elevadas plusvalías para los inversores" (BOE, 2014: 93.219).

En España, desde sus inicios, el término capital riesgo engloba tanto las inversiones realizadas en las primeras fases de desarrollo de las empresas (venture capital) como la inversión en empresas más maduras y consolidadas (private equity), mientras que en el ámbito internacional ambos tipos de operaciones suelen distinguirse. La propia Ley 22/2014 así lo reconoce: "el capital-riesgo comprende tanto lo que se ha venido denominando venture capital, destinado a las primeras fases de desarrollo de las empresas, como private equity, término este último que incluye inversión en empresas ya maduras con una trayectoria consolidada de rentabilidad y que por lo tanto supone operaciones de mayor envergadura de reestructuración empresarial siendo necesario el recurso de las entidades de capitalriesgo a préstamos para poder financiarlas" ${ }^{11}$ (BOE, 2014: 93.220).

El capital riesgo es, por tanto, un instrumento de financiación que puede utilizarse en cualquier fase del desarrollo de una empresa, desde el lanzamiento inicial de una idea hasta la reestructuración de una compañía ya consolidada, así como en fases de expansión o crecimiento. Siguiendo el texto de la mencionada Ley 22/2014: "El capital-riesgo es una fuente de financiación de especial relevancia para todas las etapas de desarrollo de las empresas: desde el desarrollo de una idea donde el capital semilla es crucial, las primeras fases de arranque de la actividad productiva, las etapas de expansión y crecimiento donde la financiación puede permitir dar el salto cualitativo a una dimensión y madurez y competitividad mayores, hasta en los momentos en los que la empresa ya está consolidada donde la financiación puede ser necesaria por diversos motivos como la salida a bolsa o la reestructuración o la venta de la misma" (BOE, 2014: 93.219).

En su informe de 2014, la Asociación Europea de Capital Riesgo (European Venture Capital Association o EVCA) define la inversión semilla o seed ${ }^{12}$ como la financiación proporcionada con fines de investigación, asesoramiento y desarro-

${ }^{10}$ Ley 22/2014, de 12 de noviembre, por la que se regulan las entidades de capital-riesgo, otras entidades de inversión colectiva de tipo cerrado y las sociedades gestoras de entidades de inversión colectiva de tipo cerrado, y por la que se modifica la Ley 35/2003, de 4 de noviembre, de Instituciones de Inversión colectiva, aprobada para incorporar al derecho nacional la Directiva 2011/61/UE del parlamento europeo y del Consejo, de 8 de junio de 2011, relativa a los gestores de fondos de inversión alternativa, dentro de la que se incluyen, de forma explícita, las entidades de capital-riesgo (BOE, 2014).

${ }^{11}$ La ley está refiriéndose aquí a las compras apalancadas (LBOs).

${ }^{12}$ En España el término "incubación” o "incubadora" suele hacer referencia a la actividad inversora de tipo semilla. 
llo inicial de una idea antes de que el negocio haya alcanzado la fase de start-up. La financiación start-up sería aquella proporcionada a empresas para desarrollo de productos y comercialización inicial de los mismos. Las empresas pueden estar bien en proceso de constitución, bien establecidas recientemente, pero todavía no se ha producido la venta comercial de sus productos.

Se puede concluir que una industria de capital riesgo dinámica y que asigna recursos de forma eficiente reduce el tamaño del denominado "equity gap" (término empleado en ocasiones para compañías que no son tan pequeñas como para funcionar únicamente con financiación personal - lo que coloquialmente se conoce como friends and family, ahorros personales del emprendedor-, ni tan grandes y establecidas como para acceder a las fuentes de financiación tradicionales), creando un clima propicio para los emprendedores (el denominado ecosistema emprendedor).

Es importante resaltar que, adicionalmente a ser una fuente de financiación, este tipo de inversores aportan gestión y conocimientos a las empresas participadas, con el ánimo de aumentar su valor cara a la desinversión futura de su participación: "La intervención de las entidades de capital riesgo supone no sólo la ventaja de la financiación obtenida por la empresa, sino que, a través de la participación de profesionales cualificados en la gestión de estas entidades que aportan su conocimiento y experiencia, contribuye a importantes mejoras en la eficiencia en la gestión de las empresas financiadas y la difusión de conocimientos" (BOE, 2014: 93.220).

Así, el capital riesgo es mucho más que un mero intermediario financiero ${ }^{13}$, ya que se involucra activamente en la operativa y en la estrategia de las empresas participadas (utilizando prácticas de negocio más flexibles e innovación constante en la gestión de operaciones) y emplea mejores políticas de gobierno corporativo (consejos de administración más pequeños y con reuniones más frecuentes, o remuneración a directivos ligada a medidas de rendimiento de la empresa a largo plazo) ${ }^{14}$.

Aunque habitualmente las operaciones de reestructuración empresarial de empresas ya maduras son las que suponen inversiones de mayor envergadura y pueden tener más repercusión mediática, el capital riesgo es quizá más importante para las empresas que se encuentran en su fase inicial, puesto que es estos casos la aportación de fondos es vital para la supervivencia del negocio y además la participación de profesionales cualificados y con experiencia en la gestión de las mismas puede resultar clave. Para el caso concreto de inversión venture en las primeras fases de desarrollo empresarial, el capital riesgo crea un gran valor añadido con el apoyo que proporciona tras la inversión, incluyendo aspectos como ayuda

${ }^{13}$ La teoría financiera tradicional atribuye a los intermediarios financieros una labor centrada sobre todo en la obtención de información, control y supervisión, que lleva a disminuir problemas de moral hazard o selección adversa derivados de las hipótesis de información asimétrica.

${ }^{14}$ Muchos estudios empíricos avalan la existencia de estas prácticas. Véase, por ejemplo, Strömberg (2009) para una recopilación de los mismos. 
a la hora de financiarse, sistemas de información, desarrollo del plan de negocio y de marketing, contratación y operaciones de fusión o de desinversión.

Este valor añadido del capital riesgo en la gestión empresarial es ampliamente reconocido y valorado por los emprendedores. El trabajo de Hsu (2004) analiza una muestra de 148 ofertas financieras realizadas sobre 51 empresas start-up de alta tecnología, y observa que las ofertas de los fondos de capital riesgo con mejor reputación tenían una probabilidad tres veces más alta de ser aceptadas a pesar de suponer un descuento en la valoración de entre un 10-14\% respecto a otras ofertas. Para Hsu estos resultados confirman la idea de que los inversores de capital riesgo no son tan sólo un intermediario financiero que proporciona fondos a empresas jóvenes con problemas de capital, sino que facilitan una serie de servicios "extra-financieros" por los que un emprendedor está dispuesto a asumir un coste, si percibe una diferencia en la calidad de los mismos entre distintos inversores ${ }^{15}$. En este sentido, una inyección de capital no sería diferente de otra, pero la calidad de estos servicios financieros adicionales aportan un valor al emprendedor que le llevaría a aceptar un descuento en el momento actual con la esperanza de que la participación que aún mantiene en la empresa sea más valiosa en el futuro fruto de la colaboración con este inversor.

En esta misma línea, Hellmann y Puri (2002) estudian empíricamente el impacto que la inversión de venture capital puede tener en el desarrollo de empresas nuevas. Analizan una muestra de 170 start-ups tecnológicas de Silicon Valley y concluyen que en empresas con inversores de capital riesgo se produce una mayor profesionalización de las políticas corporativas (a nivel de gestión de recursos humanos, adopción de incentivos o contratación de directivos). Según estos autores, el capital riesgo influye en la gestión de la empresa al más alto nivel, desempeñando una función que va más allá del papel habitual de los intermediarios financieros tradicionales, y observan que este efecto es mayor en los estados más tempranos de vida de la empresa.

El presente artículo se centra sobre todo en el papel del capital riesgo como financiador de iniciativas empresariales y de empresas de reciente creación, es decir, en su faceta de venture capital (capital semilla, financiación de start-ups y empresas jóvenes).

\subsection{Emprendedores, capital riesgo, innovación y crecimiento económico: el ecosistema emprendedor}

Los inversores de capital riesgo son intermediarios financieros cualificados que pueden reducir las asimetrías de información entre empresas y mercado, especialmente pronunciadas en el caso de emprendedores y start-ups, y proporcionan por

\footnotetext{
${ }^{15}$ Este autor recoge en su trabajo algunas afirmaciones que ilustran esta idea: "como emprendedor, es mucho más importante de quién obtienes el dinero, que cuánto obtienes o cuánto pagas por él" o "de dónde provienen los fondos es a menudo más relevante que sus condiciones financieras".
} 
tanto financiación a negocios que no estaría disponible de otra forma. De hecho, la actividad de capital riesgo se especializa en lidiar con estos problemas de riesgo e información asimétrica, conectando en la práctica a inversores que disponen de riqueza con los emprendedores que generan ideas e iniciativas empresariales ${ }^{16}$. Tradicionalmente estos inversores tienden precisamente a concentrar su inversión en las fases iniciales de desarrollo de empresas con alto riesgo y muchas opciones de crecimiento, donde las asimetrías de información son mayores y donde se producen más costes de agencia. El capital riesgo acepta los costes de monitorización y seguimiento de la inversión, recopilando información de forma periódica y manteniendo siempre la opción de abandonar proyectos que no evolucionan de la forma esperada.

El capital riesgo trata de enfrentarse a estos problemas de información asimétrica mediante el análisis y escrutinio minucioso de las compañías antes de invertir, y el control y monitorización detallada de las mismas con posterioridad a la inversión. Para ello utilizan herramientas como: proporcionar el dinero de forma escalonada en sucesivas "rondas de financiación" a lo largo del tiempo; sindicación de la inversión entre varias firmas de capital riesgo; tomar puestos en el consejo de dirección de la compañía en la que invierten e incluir en la compensación a los directivos incentivos como las opciones sobre acciones de la empresa. La existencia de rondas de financiación es uno de los mecanismos más efectivos de control en manos de los inversores de capital riesgo. Las inyecciones de capital en forma escalonada mantienen al emprendedor o a los directivos más centrados y atentos durante todo el proceso, reduciendo las pérdidas ocasionadas por malas decisiones. El inversor puede aumentar la duración de la financiación reduciendo la frecuencia de los controles y revisiones periódicas conforme la empresa se va estableciendo y la dirección de la misma se va asentando.

El capital riesgo resulta así un inversor especialmente preparado para manejar los riesgos inherentes a la actividad emprendedora, y dispuesto a prestar financiación en casos en los que otro tipo de capital se retraería. En esta línea, en el último informe publicado por la Organización para la Cooperación y el Desarrollo Económicos (OCDE, 2014) dentro de la serie Entrepreneurship at a Glance, se resalta la relevancia del venture capital como una forma de financiación complementaria o sustitutiva de la tradicional financiación bancaria, especialmente importante para aquellas empresas de nueva creación con un potencial de crecimiento e innovación, pero que aún no cuentan con una trayectoria y un modelo de negocio probados.

\footnotetext{
${ }^{16}$ Existen varios trabajos académicos que estudian la información asimétrica en la inversión de capital riesgo bajo la perspectiva del conflicto de agencia tratando de captar la esencia de la relación entre el emprendedor y el inversor de capital riesgo. Véase, por ejemplo, Amit, Glosten y Muller (1990) o Sahlman (1990). Puede consultarse también Gompers (1995), Gompers y Lerner (2001) o Sahlman (1990) sobre los mecanismos que utiliza el capital riesgo para gestionar el riesgo y las asimetrías informativas en las empresas en las que invierte.
} 
Muchos estudios avalan la idea de que la actividad de capital riesgo favorece especialmente esta tan deseada innovación. Hellman y Puri (2000) estudiaron una muestra de empresas de reciente creación en Silicon Valley entre 1994 y 1997, clasificándolas en "innovadoras" (las primeras en introducir productos o servicios nuevos para los que no hay sustitutivos en el mercado) o "imitadoras" (también ofrecen productos relativamente nuevos, pero no son las que primero entran en un determinado mercado, por lo que compiten en otros aspectos y no en innovación). Según estos autores, es mucho más probable que las empresas innovadoras consigan financiación a través del capital riesgo que las imitadoras. También observan que la presencia de capital-riesgo en una empresa innovadora acorta significativamente el tiempo que se tarda en lanzar al mercado un producto nuevo. Kortum y Lerner (2000) estudian la influencia del capital riesgo en la producción de patentes (como proxy de la innovación empresarial) en veinte industrias productivas norteamericanas a lo largo de tres décadas. Según estos autores, la inversión de capital riesgo está asociada a un incremento de patentes, y por tanto tiene un impacto en innovación. Calculan que un dólar de inversión proveniente de capital riesgo resulta tres veces más efectivo para producir resultados de innovación como patentes que un dólar invertido de la forma tradicional en $\mathrm{I}+\mathrm{D}$ por parte de la propia empresa. Estiman también que aunque la inversión de capital riesgo en I+D empresarial entre 1983 y 1992 supuso alrededor de un $3 \%$, fue responsable de un $8 \%$ de la innovación industrial en EE. UU. durante ese tiempo. En este sentido, Fraser-Sampson (2013) afirma que aunque las inversiones de capital riesgo tipo venture representan típicamente alrededor de un $1 \%$ de la inversión anual total en EE. UU., las empresas financiadas con estos fondos se estima que generan alrededor de un 13\% del PIB anual de ese país.

Por consiguiente, al financiar estos proyectos, el capital riesgo actúa como mecanismo de detección y estímulo de la innovación técnica y económica. Puesto que el conocimiento generado a través de inversiones en $\mathrm{I}+\mathrm{D}$ y en capital humano no parece trasladarse automáticamente al crecimiento económico, se ha identificado la actuación de los emprendedores como uno de los mecanismos necesarios para canalizar el conocimiento desde las fuentes donde se origina hacia las empresas que lo comercializan y generan rentabilidad con estas nuevas ideas. Con otras palabras, el ecosistema emprendedor puede servir de puente entre los centros de conocimiento (como son: universidades o laboratorios) y el mercado, es decir, entre la innovación técnica y el crecimiento económico. Fraser-Sampson (2010) señala que es un error común identificar la inversión en venture capital con el desarrollo de nuevas tecnologías, ya que lo que estos inversores buscan es desarrollar nuevas aplicaciones de tecnologías ya existentes, con el fin de lograr un impacto comercial significativo. Lo cual lleva a pensar que el capital riesgo, incluso en las fases iniciales de la vida de la empresa, no está preparado para aceptar "riesgo tecnológico" sino para asumir "riesgo de mercado". 
La evidencia empírica ${ }^{17}$ muestra que el capital riesgo tiene un impacto positivo sobre la generación de empleo, la productividad y la innovación de las empresas, lo que sugiere que también puede ejercer un efecto positivo sobre el crecimiento económico ${ }^{18}$. Estos motivos justifican perfectamente la intervención del sector público en la promoción del ecosistema emprendedor y del capital riesgo. A modo de ejemplo, las palabras de Richard Pelly, en su función de Chief Executive del Fondo Europeo de Inversiones (FEI) sirven para resumir esta idea: "el objetivo de mejorar la disponibilidad de capital riesgo para las PYME europeas innovadoras y de alto crecimiento (...) fomenta la innovación, la investigación y el desarrollo, el emprendimiento, el crecimiento y el empleo" (Pelly, 2013).

\section{INICIATIVAS PÚBLICAS PARA PROMOVER EL ECOSISTEMA EMPRENDEDOR Y EL CAPITAL RIESGO}

En la actualidad, las medidas orientadas a estimular el crecimiento económico para promover la actividad de las pequeñas empresas y de los emprendedores de nuevos negocios están acaparando gran parte de la atención pública. Y a veces, estas medidas son indistinguibles de las destinadas al fomento y promoción de la industria de capital riesgo, llegando incluso a considerar el desarrollo del sector del capital riesgo como parte de las condiciones marco para estimular un espíritu empresarial innovador (OCDE, 2014). En este sentido, un ejemplo reciente de este tipo de medidas en España es la nueva figura de la ECR-Pyme introducida por primera vez en la Ley 22/2014 de 12 de noviembre a la que ya se ha hecho referencia. Esta nueva figura pretende impulsar el sector del capital riesgo dirigido a las etapas más tempranas de desarrollo de las empresas, ofreciendo a las mismas una alternativa eficaz a la financiación bancaria, mediante una flexibilización de su coeficiente obligatorio de inversión que permite hasta cierto punto al capital riesgo invertir también en la PYME a través de instrumentos de deuda. Es interesante añadir que la ley obliga específicamente a las ECR-PYME a prestar asesoramiento a las PYME en las que participa, reforzando la idea de que el valor añadido en la gestión es uno de los aspectos claves de los inversores de capital riesgo.

En esta línea, por ejemplo, Lerner y Tag (2013) realizaron un estudio comparativo de los sectores de capital riesgo en Estados Unidos y Suecia. El relativo retraso inicial de esta actividad en Suecia respecto a Estados Unidos es achacado

\footnotetext{
${ }^{17}$ Véase Bernstein et al (2010).

${ }^{18}$ Bolevska (2014), recoge una revisión de los modelos que relacionan la actividad de capital riesgo y el crecimiento económico. Aunque, como señala Strömberg (2009), es difícil encontrar estudios rigurosos que demuestren el impacto del capital riesgo en el PIB de un país, ya que surge el problema de cómo controlar la causalidad inversa, es decir, el efecto que a su vez tiene el crecimiento de un país sobre la inversión en capital riesgo.
} 
por estos autores a la diferencia existente en ciertas variables legales y económicas, especialmente el desarrollo del mercado financiero y el sistema fiscal. Sin embargo, a pesar de este punto de partida, medidas mucho más activas por parte del gobierno sueco encaminadas a apoyar la industria del capital riesgo, junto con la liberalización de los mercados financieros, han provocado un despegue significativo de la actividad de capital riesgo en este país. En la actualidad, el mercado sueco de capital riesgo se encuentra entre los diez mercados más activos del mundo (en términos de inversiones como porcentaje del PIB). Este tipo de intervenciones sirven para demostrar la eficacia de las medidas de apoyo público al sector del capital riesgo, y pueden animar a otros gobiernos a realizar intentos en el mismo sentido.

Por esta razón, desde el sector público se trata de propiciar y favorecer la actividad del sector de capital riesgo, bien de una forma indirecta tratando de crear un entorno institucional adecuado, bien a través de la participación directa por parte del sector público en fondos o programas de capital riesgo.

\subsection{Medidas indirectas: el entorno institucional}

Diversos estudios que se remontan hasta la década de los 80 del pasado siglo resaltan la importancia que en la actividad de capital riesgo tienen, entre otros factores: el entorno legal, el desarrollo de los mercados financieros, el sistema fiscal, la regulación del mercado de trabajo o la inversión pública en $\mathrm{I}+\mathrm{D}^{19}$. En principio, el desarrollo de los mercados financieros parece ser una de las variables más importantes, ya que habitualmente va unido a una economía de mercado y a una sociedad con un cierto grado de conocimiento y sofisticación financiera, lo que propicia la actividad emprendedora y la inversión de capital riesgo. Además, un mercado de valores dinámico proporciona al negocio de capital riesgo una de las principales oportunidades de desinversión, como son las salidas a bolsa. A su vez, el éxito de las estrategias de salida o desinversión influyen en el proceso de captación de nuevos fondos o en la inversión de los mismos ${ }^{20}$. El beneficio de la financiación y las habilidades de gestión proporcionadas por el capital riesgo en su actividad más puramente venture es máximo durante las fases iniciales del ciclo de vida de las empresas. Una vez que la empresa ha crecido y empieza a madurar, le resulta relativamente más sencillo atraer inversores u obtener financiación a través de deuda. En esos momentos, el expertise y el dinero proveniente del capital riesgo podrían ser utilizados de forma más eficiente en otras iniciativas.

\footnotetext{
${ }^{19}$ Para una revisión de los principales trabajos doctrinales sobre el impacto de estas variables en la actividad de capital riesgo, véase Lerner y Tag (2013).

${ }^{20}$ Como recuerdan Gompers y Lerner (2001), todas las fases de inversión están relacionadas entre sí, formando lo que ellos denominan el "venture cycle".
} 
Black y Gilson (1998) demuestran la importancia del desarrollo de los mercados financieros comparando el sector de capital riesgo en Estados Unidos, Japón y Alemania, mientras que Jeng y Wells (2000) comprueban empíricamente que la industria de capital riesgo es más activa en países con mayor número y frecuencia de salidas a bolsa. Estos mismos autores señalan que cuando un inversor de capital riesgo realiza una salida a bolsa exitosa de una empresa participada, está dejando patente su habilidad, lo que debería suponerle una ventaja a la hora de conseguir capital para futuros fondos. En la misma línea se encuentran las medidas de los últimos años para impulsar los nuevas mercados alternativos bursátiles, como es el caso del MAB en España, que vio la luz en 2006 con el objetivo de dotar de financiación a pequeñas empresas en expansión. Este efecto positivo de los "nuevos" mercados para empresas jóvenes en el sector del capital riesgo y en los emprendedores se demuestra en el estudio de Da Rin et al. (2005).

Especialmente pertinente para el objeto de este artículo es el trabajo de Balboa y Martí (2011), que estudian el mercado de capital riesgo en España entre 1991 y 2007, y la sensibilidad ante cambios en la tasa impositiva sobre las ganancias de capital y ante la introducción de una regulación específica para la actividad de capital riesgo. Sus resultados no muestran evidencia concluyente del efecto que tienen los cambios de la tasa fiscal de las plusvalías. Sin embargo, dichos autores sí identifican un efecto positivo y significativo sobre la captación de fondos al introducir una legislación específica para el capital riesgo. En sus propias palabras: "Este resultado es importante para el regulador, porque demuestra que el conjunto de medidas destinadas a crear un entorno favorable constituye un impulso a los mercados de capital riesgo", es decir, que las medidas regulatorias para fomentar el ecosistema emprendedor funcionan.

En Da Rin et al. (2005) se analizan datos de panel para 14 países europeos durante el periodo entre 1988 y 2001, y además del ya mencionado factor de los nuevos mercados y su influencia sobre el sector del capital riesgo, se estudian otras medidas orientadas a crear un entorno favorable para el emprendedor. Estos autores muestran como la regulación del mercado laboral puede actuar como desincentivo para los emprendedores, y observan que existe un cierto impacto positivo, aunque menor, de reducciones en la tasa fiscal de las plusvalías. Sus resultados parecen indicar que la creación de un mercado de capital riesgo activo en Europa, no dependen tanto de la disponibilidad de fondos, sino más bien de las posibilidades que los emprendedores y los inversores tengan de recibir los frutos económicos de su actividad. Si bien, conviene matizar que este trabajo fue publicado en 2005, es decir, antes del tremendo impacto negativo de la crisis económica sobre el crédito bancario y la captación e inversión de fondos de capital riesgo. De hecho, los propios autores indican que el aumento de la oferta de fondos de capital riesgo no es una variable tan relevante, salvo en los casos en los que haya condiciones restrictivas de acceso al crédito, como sería el caso de los mercados europeos de crédito en los últimos años. 
También Gompers y Lerner (1998) concluyen que las medidas más relevantes son las que aumentan el atractivo y los incentivos de la actividad emprendedora y de la inversión tecnológica, tras estudiar la sensibilidad de la captación de fondos de capital riesgo ante distintas variables: cambios regulatorios que afectan a los fondos de pensiones y a la tasa fiscal de las ganancias de capital, inversión en I+D; crecimiento económico, y reputación y rendimiento del inversor concreto. En su opinión ciertas reformas regulatorias y políticas públicas tienen un efecto positivo en la captación de fondos de capital riesgo.

Dentro de las medidas relacionadas con la regulación de las actividades financieras, vale la pena destacar la que afecta a los fondos de pensiones como aportantes de fondos. La situación de España se diferencia de otros países de su entorno, ya que la asignación que los fondos de pensiones nacionales destinan al capital riesgo no suele superar el $2 \%^{21}$ del total de recursos captados por el sector (ASCRI, 2014), mientras que los fondos de pensiones extranjeros en vehículos de capital riesgo está entre el 15\% y el 20\% (EVCA, 2014). Y la pregunta evidente es si podrían tomarse medidas por parte de las autoridades públicas españolas para activar la inversión de los fondos de pensiones en esta categoría de activos.

Gompers y Lerner (1998) ilustran el efecto de las aportaciones de los fondos de pensiones en la industria de capital riesgo en Estados Unidos, cuando en 1979 el Department of Labour aclaró la regla del "prudent man rule" 22 a la que estaban sujetos los gestores de fondos de pensiones en la Employment Retirement Income Security Act (ERISA). Hasta ese momento, los gestores de fondos de pensiones evitaban invertir en activos de capital riesgo, por temor a que se considerasen inversiones imprudentes. En ERISA se aclara que las inversiones se considerarán prudentes no en función de su riesgo como inversión individual, sino por su contribución al riesgo de la cartera, lo que abrió las puertas para que los fondos de pensiones consideraran el capital riesgo entre las categorías de activos donde invertir. El citado estudio confirma el efecto positivo de esta medida no sólo en la cantidad de fondos aportados al sector, sino también en el número de nuevos fondos, especialmente en los dedicados a empresas jóvenes en las primeras fases de desarrollo ${ }^{23}$.

En el caso español, a pesar de que tanto la regulación de planes y fondos de pensiones como la relativa a entidades aseguradoras incluyeron la inversión en capital riesgo como activo apto para cobertura de provisiones técnicas hace tiempo ${ }^{24}$, las

${ }^{21}$ Aunque, en 2013 , la aportación de los fondos de pensiones fue anormalmente alta, llegando al 8\% del total de recursos.

${ }^{22}$ Lo que en España se conoce como la actuación propia de un "buen padre de familia".

${ }^{23}$ El mencionado trabajo de Kortum y Lerner (2000) también utiliza el cambio regulatorio de 1979, precisamente para aislar de otros factores, como puede ser el aumento del número de empresas, el papel específico del capital riesgo en la innovación.

${ }^{24}$ Para los planes de pensiones, la apertura se produjo desde el 1 de enero de 2008, en virtud del RD 1684/2007, de 14 de diciembre, que modificó el art. 70 de su reglamento y para entidades aseguradoras, desde el 20 de febrero de 2007, por los cambios introducidos en el art. 50 del ROSP por el RD 239/2007, de 16 de febrero. 
aportaciones siguen siendo, como se ha mencionado, realmente poco significativas. En los últimos años, se han venido analizando distintas opciones que, de un modo u otro, pudieran contribuir a paliar esta deficiencia y, en este sentido se han hecho llegar diversas recomendaciones al regulador entre las que podrían mencionarse: los incentivos de carácter fiscal, eliminar o disminuir el efecto de las comisiones en cascada, tanto modificando el cómputo de los límites de las comisiones como estableciendo un periodo de carencia o incluso aumentando el límite de dichas comisiones en determinadas circunstancias. En esta línea el regulador podría también tratar de incentivar las contribuciones de otros aportantes institucionales, como las compañías de seguros, para lo que se sugieren incentivos fiscales y medidas destinadas a evitar penalizar dichas inversiones desde el punto de vista de requisitos de capital.

Finalmente, los derechos de propiedad intelectual, el gasto público en I+D y las normas y prácticas de transferencia de resultados de investigación también influyen en el desarrollo de la industria local de capital riesgo ${ }^{25}$. Es evidente que una adecuada regulación en materia de propiedad intelectual es imprescindible para asegurar la rentabilidad económica de la investigación, a través de la comercialización de la innovación y sus aplicaciones prácticas. Sin embargo, aumentar la partida de gasto público destinada a I+D puede no ser suficiente. En ocasiones las políticas públicas de fomento e inversión en I+D y formación de capital humano pueden resultar decepcionantes en cuanto a su impacto en el crecimiento económico. Esta situación ocurre en muchos países europeos, lo que ha dado lugar a la expresión "la paradoja europea" para describir este fenómeno. Se haría necesario no sólo promover la investigación, sino impulsar específicamente la creación de nuevas empresas y el cuidado del ecosistema emprendedor para que actúen como conexión entre la innovación tecnológica y la comercialización de la misma. En este sentido, la transferencia de resultados entre investigadores, emprendedores e inversores de capital riesgo es clave para el ecosistema, pues estos agentes se complementan entre sí. Como dice Michelacci (2003)26, la innovación y el crecimiento precisan de investigadores que generen ideas y de emprendedores que las comercialicen. También proporciona evidencia empírica sobre el círculo virtuoso de un ecosistema emprendedor consistente, el trabajo de Samila y Sorenson (2010), que observan que la correlación entre ayudas a la investigación concedidas a universidades y el índice de patentes registradas y empresas creadas es más alta en las regiones en las que la industria de capital riesgo es más activa ${ }^{27}$.

${ }^{25}$ Véase, entre otros, Gompers y Lerner (1998), Da Rin et al (2005) y Acs et al. (2012).

${ }^{26}$ Esta idea se expone también en el mencionado estudio de Acs et al. (2012).

${ }^{27}$ Puede consultarse Carlsson et al. (2009) para una revisión histórica de la relación entre generación de conocimiento, emprendedores y crecimiento económico. Estos autores distinguen entre nuevas cotas de saber y conocimiento con utilidad económica, analizando el papel de las universidades, escuelas de ingeniería, laboratorios industriales e I+D corporativo. 


\subsection{Medidas directas: programas específicos de ayuda a emprendedores y estímulo del capital-riesgo. Especial atención al caso español}

Han sido numerosos los programas de naturaleza pública dirigidos a la reactivación del sector que tratan de financiar iniciativas emprendedoras o fondos de capital riesgo. Un ejemplo a nivel paneuropeo sería la labor del Fondo Europeo de Inversiones (FEI). El FEI, que gestiona recursos en nombre de la Comisión Europea, el BEI y otros organismos, facilita ayudas a las PYME como inversor anticíclico en tiempos de dificultad económica, utilizando una amplia gama de intermediarios financieros seleccionados (socios tecnológicos, fondos de capital riesgo y de crecimiento, entre otros) de toda Europa. El FEI actúa en las fases principales de desarrollo de una empresa, desde la primera etapa de propiedad intelectual hasta la expansión y crecimiento de la misma ${ }^{28}$. Normalmente estructura su actuación a través de los fondos europeos de capital riesgo y de crecimiento, pero atrayendo también capital del sector privado y trabajando con inversores profesionales para atender oportunidades del mercado. Esta colaboración estrecha entre financiación pública y capital privado parece ser una de las claves para el éxito de este tipo de iniciativas. A modo de ejemplo, en 2012, el FEI destinó 1.300 millones de euros a 63 fondos, lo que movilizó más de 7.000 millones de euros de otros inversores, es decir, el tejido empresarial se benefició de una mayor oferta de fondos debido al efecto multiplicador de este programa.

En esta línea de actuación, para el caso concreto de España, el FEI invierte de forma activa y directa en numerosos fondos de capital riesgo nacionales, además de gestionar Neotec Capital Riesgo. Este programa fue creado en febrero de 2006 en colaboración con CDTI, AXIS y varias entidades inversoras privadas. Con el mismo fin de alentar a los emprendedores y suplir las carencias en su financiación, el FEI está extendiendo su actuación a otras iniciativas, como es el caso del fondo Isabel la Católica EAF Spain del Instituto de Crédito Oficial (ICO), en el que se coinvierte conjuntamente con business angels.

El Instituto de Crédito Oficial puso en marcha, a mediados de 2013, el fondo Fond-ICO Global ${ }^{29}$ con el propósito de estimular la financiación no bancaria de proyectos que combinen innovación y emprendimiento, invirtiendo en empresas

${ }^{28}$ Por ejemplo, empresas innovadoras y de alto crecimiento como Rovio, Shazam, Skype, Hailo o Spotify han sido financiadas de forma indirecta por el FEI en sus primeras fases de desarrollo.

${ }^{29}$ Fond-ICO Global está inscrito en la Comisión Nacional del Mercado de Valores (CNMV) desde el pasado 24 de mayo de 2013 y está gestionado por Axis Participaciones Empresariales SGECR S. A., que es una sociedad participada al 100\% por el ICO. Desde su constitución en 1986, la sociedad Axis ha realizado numerosas inversiones y actualmente gestiona también otros fondos como son: Fond-ICO pyme (destinado a apoyar a las pequeñas y medianas empresas en sus planes de expansión) y Fond-ICO infraestructuras (participa en proyectos de infraestructuras). Para más detalle sobre los fondos gestionados y la historia de Axis, como sociedad gestora de capital riesgo puede consultarse http://www.axispart.com. 
en cualquier fase de desarrollo y buscando la mejora de su competitividad e internacionalización. Se trata del primer "Fondo de Fondos 30 " público de capital riesgo creado en España con el objetivo de promover la creación de fondos de capital riesgo de gestión privada que realicen inversiones en empresas españolas. FondICO Global se creó con un horizonte temporal de cuatro años para realizar inversiones y se ha dotado inicialmente con 1.200 millones de euros. Si bien, durante esos cuatro años se estima que puedan movilizarse recursos de inversores privados muy superiores a esa cifra, ya que la idea inicial fue que Fond-ICO Global pudiese actuar como "inversor ancla" para atraer otros inversores privados nacionales e internacionales que proporcionen financiación a las empresas españolas, sea cual sea su fase de desarrollo (ASCRI, 2014). De hecho, no debe olvidarse que la creación de Fond-ICO Global formaba parte de las medidas propuestas por el Gobierno de España, en febrero de 2013, para impulsar la desintermediación bancaria y el capital riesgo dentro del "Plan de Estímulo Económico y Apoyo al Emprendedor ${ }^{31} "$.

Por el momento, parece que la iniciativa de lanzar un "Fondo de Fondos" en España está siendo exitosa y que Fond-ICO Global se ha convertido en una pieza esencial en la recuperación del sector del capital riesgo español, sirviendo como catalizador en la creación de nuevos fondos de capital riesgo. Entre las cuatro convocatorias realizadas hasta la fecha, hay un objetivo de inversión total de 9.531 millones de euros de los cuales sólo 755 millones de euros corresponden a la aportación de Fond-ICO Global. Asimismo, los fondos seleccionados se han comprometido a invertir como mínimo 2.568 millones de euros en empresas españolas, lo que representa un efecto multiplicador promedio de 3,4 veces sobre la denominada "inversión ancla" realizada por Fond-ICO Global. Desde su creación, la evolución de Fond-ICO Global ha sido muy positiva y en poco tiempo ha logrado atraer no sólo capital privado nacional sino el capital de inversores internacionales. En la tabla 1 se muestra la información correspondiente a cada convocatoria, tanto en lo relativo a los candidatos como a las gestoras de capital riesgo seleccionadas y los fondos creados. Puede apreciarse que hay un número importante de candidatos

\footnotetext{
${ }^{30}$ Este tipo de "Fondo de Fondos" público que no invierte directamente en empresas, sino que invierte en otros fondos (que serán los que inviertan en empresas), ya está en funcionamiento en otros países y la experiencia ha sido positiva. Es el caso, entre otros de Reino Unido o Israel.

${ }^{31}$ Recordemos que el "Plan de Estímulo Económico y Apoyo al Emprendedor" fue anunciado por el Presidente del Gobierno en el Debate sobre el Estado de la Nación del 20 de febrero de 2013. Y en dicho plan, se plasmó la intención de movilizar 2.176 millones de euros como impulso a la desintermediación bancaria y al capital riesgo y, entre las medidas a llevar a cabo, se anunció "la constitución de un Fondo de Fondos encargado de licitar y adjudicar inversiones entre gestoras de capital riesgo en áreas y sectores vinculados a la internacionalización y la mejora de la competitividad". Un resumen de las medidas propuestas se encuentra disponible en http://www.lamoncloa.gob.es/documents/c140-e3a0planestÍmulofinalden2013.pdf.
} 
internacionales en las diferentes categorías (venture capital, capital expansión o deuda) y cuál ha sido el volumen total de fondos movilizados en cada convocatoria.

En los próximos años está previsto que se lleven a cabo nuevas convocatorias de Fond-ICO Global, que se irán adaptando a la demanda de los inversores y a la situación del mercado en cada momento.

\section{Tabla 1. Convocatorias Fond-ICO Global}

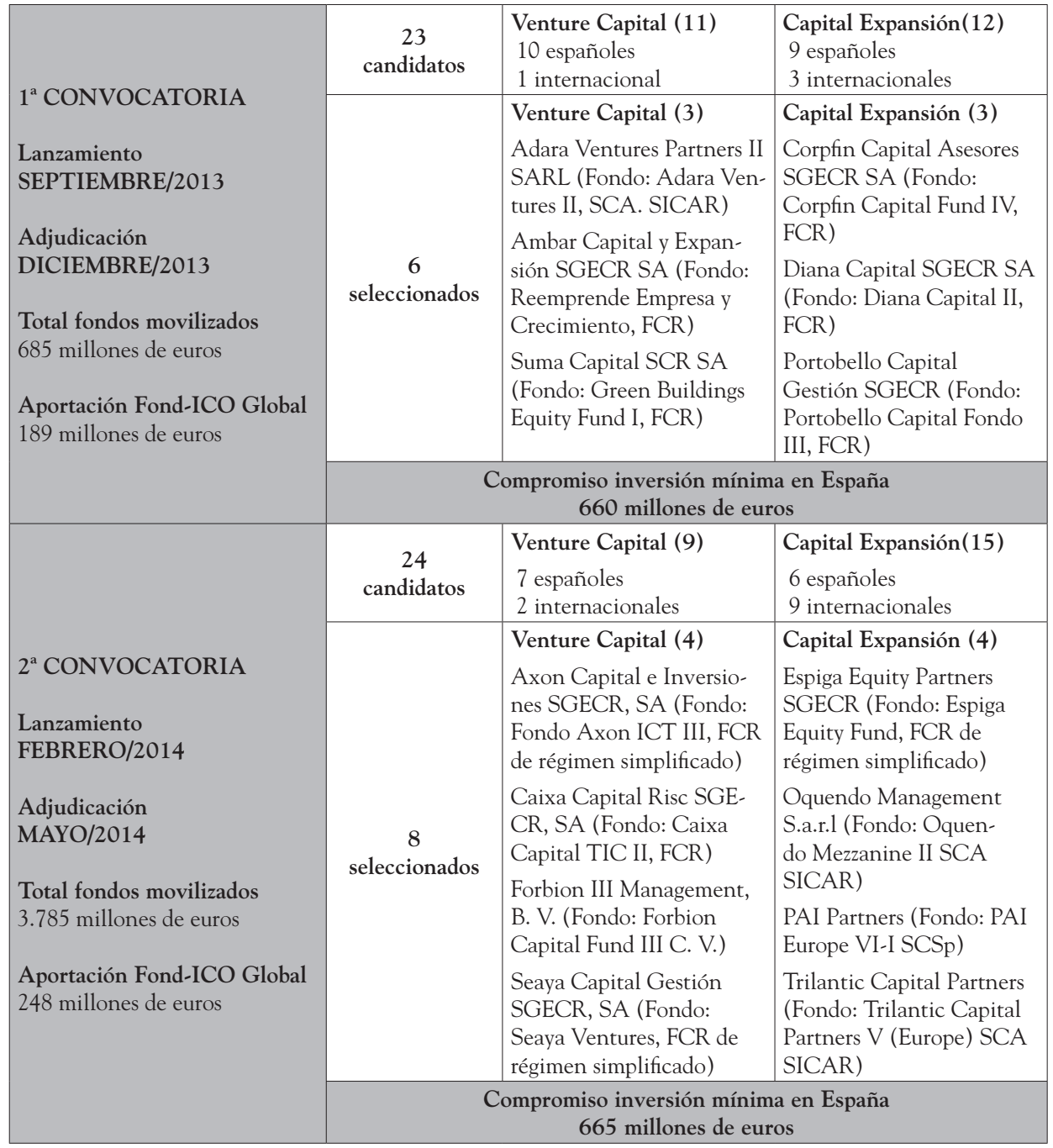


EMPRENDEDORES Y CAPITAL RIESGO EN ESPAÑa: EL CASO de Fond-ICO Global

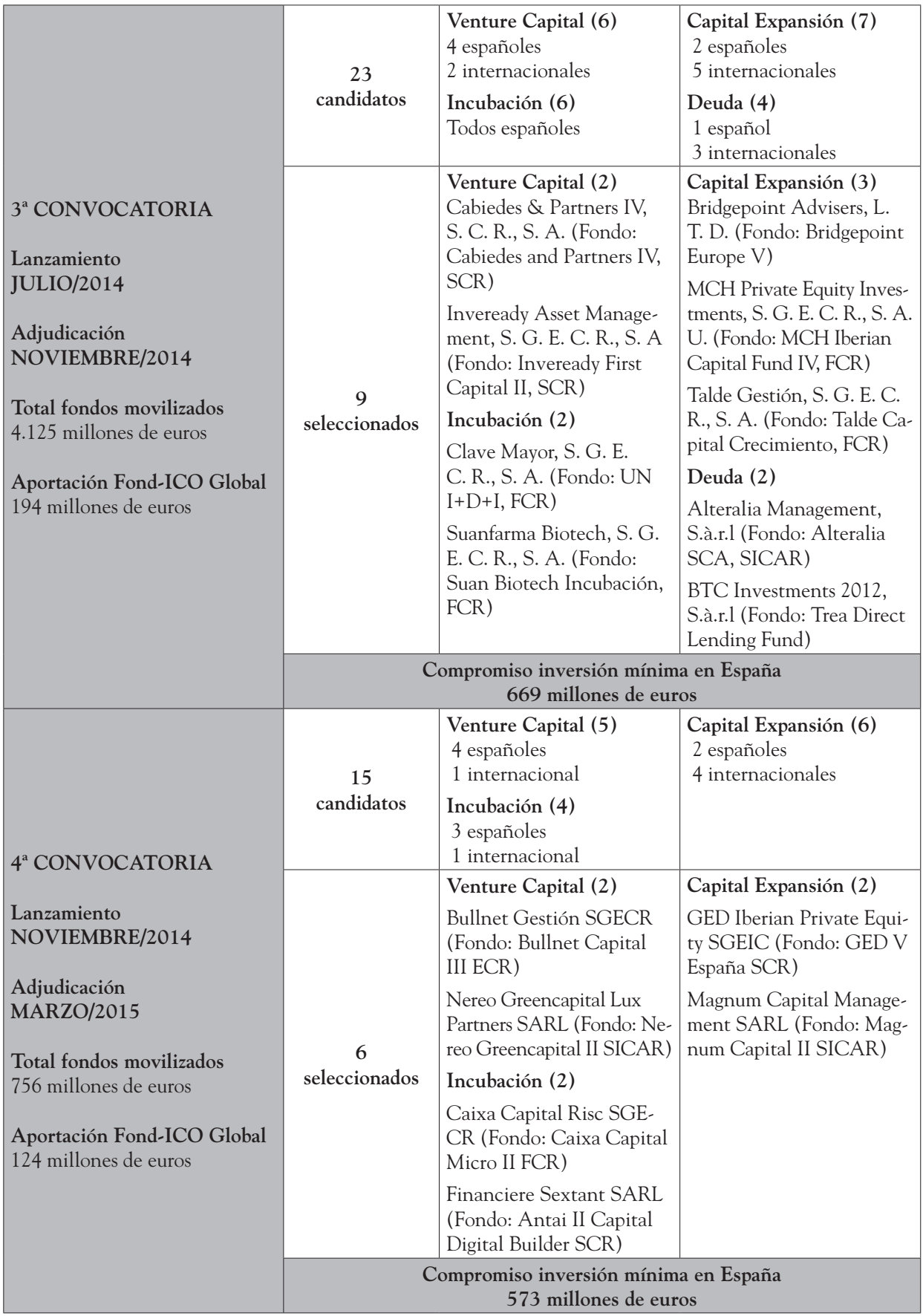

Fuente: Elaboración propia a partir de la información disponible en www.axispart.com. 
Ahora bien, sin duda alguna, el éxito de Fond-ICO Global se debe en gran medida a la gestión eficiente llevada a cabo por la sociedad gestora Axis, que con la ayuda de asesores externos especializados, es la encargada de realizar la selección de los fondos y gestoras de capital riesgo privados más adecuados. Todo el proceso de valoración y selección se realiza a través de un sistema de licitación pública, respetando en cada convocatoria los principios de publicidad, concurrencia, igualdad y transparencia. En concreto, para llevar a cabo la selección de los fondos, se efectúa un proceso de evaluación y valoración de los candidatos conforme a una serie de criterios cuantitativos y cualitativos definidos en las bases de cada convocatoria y para cada una de las categorías y, posteriormente, se eligen aquellos que alcancen la mayor puntación. Atendiendo a principios de transparencia y publicidad, los criterios de evaluación utilizados (y las posibles puntuaciones) son conocidos de antemano por todos los participantes y se encuentran explicados de forma detallada dentro de las bases de cada convocatoria, las cuales están accesibles a través de la página web de la sociedad gestora Axis. En las tablas 2 y 3 se han resumido los citados criterios de evaluación contenidos en las bases correspondientes a la última convocatoria, diferenciando por tipo de fondo: Fondos de venture capital y de capital expansión (tabla 2) y fondos de incubación (tabla 3).

Adicionalmente, en las bases publicadas por $\mathrm{Axis}^{32}$ para cada convocatoria, están especificados los requisitos exigidos a los participantes. Por una parte, hay requisitos que son comunes a las diferentes categorías (incubación, venture capital, capital expansión y deuda) y, por otra, condiciones específicas para cada tipo de fondo.

Según los últimos datos publicados por la Asociación Española de Entidades de Capital Riesgo ${ }^{33}$ (ASCRI, 2014) el sector del capital riesgo en España está afianzando su recuperación, siendo especialmente positiva la evolución de la participación de fondos internacionales de venture capital. Desde ASCRI se reconoce el papel clave que el fondo de fondos Fond-ICO Global está teniendo en la captación y distribución de nuevos recursos para fondos de capital riesgo y que gracias a su actividad se ha convertido en el principal Limited Partner español en fondos de capital riesgo.

\footnotetext{
32 Se encuentran disponibles en http://www.axispart.com/fondos-de-gestion/fond-ico-global/seleccion-de-fondos. Los requisitos exigidos, aún con una base común, pueden ir variando en cada convocatoria.

${ }^{33}$ En colaboración con Webcapitalriesgo.com, que son los encargados de recoger y tratar la información estadística.
} 
Tabla 2

Criterios de evaluación Fond-ICO Global: Venture Capital y Capital Expansión

\begin{tabular}{|c|c|}
\hline CRITERIOS CUANTITATIVOS & $\begin{array}{c}\text { Ponderación } \\
90 \%\end{array}$ \\
\hline $\begin{array}{l}\text { ESTRATEGIA DE INVERSIÓN } \\
\text { - Experiencia previa de la firma } \\
\text { - Consistencia con los fondos anteriores en términos de tamaño de inversión y } \\
\text { del fondo, estrategia, geografía e industria } \\
\text { - Volumen de inversión a realizar en España }\end{array}$ & $13,5 \%$ \\
\hline $\begin{array}{l}\text { EQUIPO DE INVERSIÓN } \\
\text { - Experiencia relevante del equipo de inversión del fondo } \\
\text { - Experiencia del equipo trabajando en España } \\
\text { - Experiencia del equipo trabajando de manera conjunta } \\
\text { - Compromiso del equipo gestor y/o de la gestora del fondo }\end{array}$ & $13,5 \%$ \\
\hline $\begin{array}{l}\text { TRACK RECORD } \\
\text { - Retornos totales en términos de TIR bruta y múltiplo bruto } \\
\text { - Experiencia en desinversiones totales y parciales con retorno positivo } \\
\text { - Compañías por desinvertir: número de compañías por desinvertir y objetivo } \\
\text { de compañías a invertir del nuevo fondo } \\
\text { - Ampliaciones de capital realizadas sobre el total del capital invertido en fon- } \\
\text { dos anteriores (1) }\end{array}$ & $18,0 \%$ \\
\hline $\begin{array}{l}\text { BASE INVERSORA Y CAPTACIÓN DE CAPITAL } \\
\text { - Nivel de institucionalización e internacionalización de la base inversora } \\
\text { - Cantidad de capital captado hasta la fecha por el fondo } \\
\text { - Volumen solicitado a Fond-ICO Global sobre el tamaño objetivo y volumen } \\
\text { a invertir en España }\end{array}$ & $22,5 \%$ \\
\hline $\begin{array}{l}\text { REMUNERACIÓN } \\
\text { - Comisión de gestión y éxito para un hurdle rate (retorno preferente) del 8\% } \\
\text { - Rentabilidad mínima a partir de la cual se daría la recompra de la participa- } \\
\text { ción de Axis }\end{array}$ & $18,0 \%$ \\
\hline $\begin{array}{l}\text { OTROS } \\
\quad \text { - Gestora / Fondo inscrito en España } \\
\text { - Oficina / Equipo de inversión dedicado a España }\end{array}$ & $4,5 \%$ \\
\hline CRITERIOS CUALITATIVOS & $\begin{array}{c}\text { Ponderación } \\
10 \%\end{array}$ \\
\hline $\begin{array}{l}\text { - Equipo - dimensión respecto al tamaño del fondo/estrategia/rotación del } \\
\text { equipo/otros } \\
\text { - Equipo - estructura de retribución /promoción/formación/sucesión del equi- } \\
\text { po gestor } \\
\text { - Proceso de toma de decisiones - proceso estipulado de inversión, equipo indepen- } \\
\text { diente, presencia comité de inversión, calidad de los papeles de inversión } \\
\text { - Calidad del reporting y monitorización de las compañías } \\
\text { - Métodos de valoración de las inversiones en cartera } \\
\text { - Uso de políticas de buen gobierno, medioambientales y sociales }\end{array}$ & \\
\hline
\end{tabular}

Fuente: Elaboración propia con información de AXIS.

(1) No se considera para valorar los fondos de venture capital 
Tabla 3

Criterios de evaluación Fond-ICO Global: Incubación

\begin{tabular}{|c|c|}
\hline CRITERIOS CUANTITATIVOS & $\begin{array}{c}\text { Ponderación } \\
80 \%\end{array}$ \\
\hline $\begin{array}{l}\text { TRACK RECORD DEL EQUIPO DE INVERSIÓN/DEL PARTICIPAN- } \\
\text { TE } \\
\text { - Experiencia del equipo en el ámbito (sector/industria) en los que se } \\
\text { enfocará el Fondo (media de años) } \\
\text { - Experiencia del equipo en inversiones: compañías en el ámbito de la } \\
\text { incubación en España (media de años) y/o a nivel internacional (nú- } \\
\text { mero de compañías) } \\
\text { - Experiencia del equipo trabajando de manera conjunta (años) } \\
\text { - Experiencia del equipo como consejeros de compañías ( } n^{\circ} \text { de compañías) } \\
\text { - Experiencia del equipo como gestores de compañías ( }{ }^{\circ} \text { de compañías) } \\
\text { - Experiencia del participante como inversores de compañías ( }{ }^{\circ}{ }^{\circ} \text { de } \\
\text { compañías) } \\
\text { - Experiencia del participante en la creación de nuevas compañías ( }{ }^{\circ} \\
\text { de compañías) } \\
\text { - Proyectos promovidos a partir de spin-off basados en patentes de Cen- } \\
\text { tros de Investigación y Universidades ( }{ }^{\circ} \text { de compañías) } \\
\text { - Proyectos lanzados por el participante, que han recibido segundas ron- } \\
\text { das de financiación ( }{ }^{\circ} \text { de compañías) } \\
\text { - Proyectos promovidos por el participante, que han recibido financia- } \\
\text { ción de organismos europeos / CDTI / ENISA ( }{ }^{\circ} \text { de compañías) } \\
\text { - Experiencia del participante en propiedad intelectual (n }{ }^{\circ} \text { de patentes } \\
\text { registradas por los miembros del equipo) }\end{array}$ & $28 \%$ \\
\hline $\begin{array}{l}\text { EQUIPO DE INVERSIÓN } \\
\text { - Compromiso del equipo gestor y/o de la gestora del fondo } \\
\text { - Número de miembros del equipo en relación al número objetivo de } \\
\text { inversiones a realizar en el nuevo Fondo }\end{array}$ & $12 \%$ \\
\hline $\begin{array}{l}\text { TRACK RECORD COMO GESTORA } \\
\text { - Experiencia previa de la firma: gestión de sociedades dedicadas a la in- } \\
\text { versión en el ámbito de la incubación }\end{array}$ & $8 \%$ \\
\hline $\begin{array}{l}\text { BASE INVERSORA Y CAPTACIÓN DE CAPITAL } \\
\text { - Cantidad de capital captado hasta la fecha por el fondo } \\
\text { - Nivel de internacionalización de la base inversora real } \\
\text { - Volumen solicitado a Fond-ICO Global sobre el tamaño objetivo y vo- } \\
\text { lumen a invertir en España }\end{array}$ & $16 \%$ \\
\hline $\begin{array}{l}\text { REMUNERACIÓN } \\
\text { - Comisión de gestión } \\
\text { - Comisión de éxito para un hurdle rate (retorno preferente) del 8\% }\end{array}$ & $8 \%$ \\
\hline $\begin{array}{l}\text { OTROS } \\
\text { - Acuerdos de colaboración con centros oficiales de investigación, gran- } \\
\text { des empresas y organizaciones internacionales (número de acuerdos) } \\
\text { - Gestora / Fondo inscrito en España }\end{array}$ & $8 \%$ \\
\hline
\end{tabular}




\begin{tabular}{|c|c|}
\hline CRITERIOS CUALITATIVOS & $\begin{array}{c}\text { Ponderación } \\
20 \%\end{array}$ \\
\hline $\begin{array}{l}\text { - Valoración de la estrategia de inversión actual } \\
\text { - Sectores de inversión en los que se especializa el Fondo } \\
\text { - Periodo medio de estancia y nivel de maduración de los proyectos que } \\
\text { se incuban } \\
\text { - Consistencia de la estrategia de inversión actual respecto a la imple- } \\
\text { mentada en el pasado } \\
\text { - Experiencia complementaria del equipo de inversión } \\
\text { - Compromiso y dedicación del equipo en el nuevo vehículo } \\
\text { - Equipamiento técnico de la incubadora } \\
\text { - Servicios a ofrecer a la empresa incubada (Asesoría/Auditoría/Desarro- } \\
\text { llo Negocio/Propiedad Intelectual/Búsqueda financiación/Orientación } \\
\text { tecnológica) } \\
\text { - Monitorización de las empresas incubadas } \\
\text { - Fuentes de deal flow y relaciones de los miembros del equipo } \\
\text { - Proceso de toma de decisiones } \\
\text { - Comisiones de gestión - Detalle de alineación de estrategia y comisio- } \\
\text { nes } \\
\text { - Calidad del reporting a inversores }\end{array}$ & \\
\hline
\end{tabular}

Fuente: Elaboración propia con información de AXIS.

\section{VALORACIÓN DEL ÉXITO DE LAS INICIATIVAS PÚBLICAS. ANÁLISIS DEL CASO ESPAÑOL: FOND-ICO GLOBAL}

En opinión de Lerner (2009), prácticamente todos los centros considerados punteros hoy día en cuanto a actividad emprendedora en el mundo, han tenido en su origen una intervención pública proactiva, al igual que la industria de capital-riesgo, que en su opinión ha sido configurada en gran medida a partir de actuaciones públicas, como los programas de la Small Business Investment Company (SBIC) en Estados Unidos, establecidos en 1958 y que se suele considerar el nacimiento del mercado de capital riesgo propiamente dicho en ese país. Ya desde 1953 con el establecimiento de la Small Business Administration cuya finalidad era promover y proteger los intereses de pequeñas empresas, se manifestó el interés que había en Estados Unidos por esta categoría de negocios. Resulta interesante que una de las principales actividades de la SBA fuese el desarrollo de programas educativos y de asistencia financiera a emprendedores, es decir, el centro de atención de esta administración era la habilidad de crear y hacer crecer empresas.

Un ejemplo actual en este sentido sería el "Plan Europeo de Acción para el Emprendimiento 2020", basado en tres pilares fundamentales. Los dos primeros hacen referencia a medidas indirectas de fomento de las condiciones generales 
de actuación del emprendedor, como son: reavivar la cultura emprendedora de Europa a través de educación en el emprendimiento y modificar las medidas reglamentarias y administrativas, sobre todo simplificándolas, para que el entorno empresarial sea más favorable a los emprendedores. Y el tercer pilar recoge las denominadas medidas directas, es decir, propuestas de acción concretas de apoyo a grupos de emprendedores.

Aunque parece existir consenso, tanto en el ámbito académico como en los propios mercados financieros, en esta función del sector público como catalizador necesario para lograr un ambiente emprendedor dinámico y una industria próspera de capital riesgo, no se puede afirmar que todas las iniciativas públicas que pretenden estimular la actividad de capital riesgo sean efectivas per se, existiendo cautelas y reservas importantes.

En este sentido, resultan interesantes las consideraciones expuestas por Lerner (2009) en su libro Boulevard of Broken Dreams. Why Public Efforts to Boost Entrepreneurship and Venture Capital Have Failed, and What to Do About It ${ }^{34}$, respecto a los errores más habituales en el diseño e implantación de programas gubernamentales que buscan facilitar la creación de empresas y potenciar el uso del capital riesgo. Este autor expone los principales motivos por los que la actuación pública puede fracasar en su objetivo de fomentar la actividad emprendedora y propone una serie de recomendaciones para que las políticas públicas de apoyo al emprendedor y al sector de capital riesgo sean exitosas, evitando de esta manera los errores cometidos en anteriores ocasiones.

Lerner considera que estos programas públicos pueden fallar, tanto por errores en el diseño como por fallos en la implementación de los mismos. Entre los primeros de ellos menciona a) por una parte, no tomar en consideración dónde está el verdadero interés del mercado, lo que implica invertir los fondos públicos en empresas y/o actividades en los que no tiene ningún interés el sector privado. Y, b) por otra parte, en ocasiones se ignora la realidad de los procesos de creación de empresas, lo que hace que no se espere el suficiente tiempo para obtener resultados de la inversión, que se realicen inversiones con un tamaño inapropiado (insuficientes o excesivas) o que los programas se centren en la investigación e innovación, pero no en la comercialización. En cuanto a la implementación de las programas públicos, Lerner señala varios errores a subsanar, entre otros: a) la inexistencia de mecanismos de evaluación, tanto del propio programa y su evolución como de las empresas o fondos que reciben la financiación, hasta el punto de que en ocasiones los emprendedores reciben la ayuda financiera independien-

\footnotetext{
${ }^{34}$ A pesar de que algunos puntos de este libro han sido objeto de debate posterior, el trabajo desarrollado por el profesor Lerner es un referente en el análisis de la relación entre las iniciativas públicas y el venture capital. Y esos aspectos puntuales del libro que han sido sujetos a debate (parte de la evidencia empírica), no restan validez a los argumentos expuestos en este artículo. A este respecto, puede consultarse la publicación Venture Capital, vol. 13, núm. 1, de enero 2011.
} 
temente del devenir de su iniciativa, lo que les puede llevar a desentenderse de la misma y b) el olvido de la naturaleza global de esta industria y el interés por llevar a cabo acciones locales, incluso llegando a desincentivar activamente las iniciativas extranjeras.

Lerner expone un catálogo de recomendaciones para las iniciativas públicas de apoyo al capital riesgo y a emprendedores que, según Demaria (2013), son probablemente la mejor recopilación de lo que se debe y no se debe hacer en los programas públicos de fomento del capital riesgo. En el presenta trabajo, dichas recomendaciones se han agrupado en cuatro grandes grupos, en aras a una mayor claridad expositiva. El primer grupo hace referencia a la promoción adecuada del entorno de actuación de los emprendedores (corresponde a las medidas indirectas ya mencionadas) y los otros tres grupos recogen las recomendaciones específicas acerca del diseño, aplicación y supervisión de los programas concretos (las medidas directas). Como uno de los objetivos de este artículo es mostrar una valoración del programa Fond-ICO Global a la luz de las recomendaciones teóricas propuestas para un buen diseño e implantación de los programas públicos, se irá realizando el análisis de dicho programa conforme se vayan exponiendo las diferentes recomendaciones.

\section{- Medidas indirectas}

La actividad emprendedora no existe en el vacío, no puede ser un fenómeno individual. Los programas públicos de apoyo a la actividad emprendedora no deben considerarse como una acción aislada, sino que previamente es necesario alentar y cuidar el ecosistema emprendedor. Antes de financiar iniciativas, las autoridades económicas deberían fijarse en aquellas barreras que pueden dificultar la actividad emprendedora y que quizá no siempre son tan inmediatas o evidentes. Estos esfuerzos por crear el clima emprendedor adecuado deben seguir distintas direcciones. Una de ellas es utilizar los recursos de investigación e innovación de la forma más efectiva posible, v.g. prestando más atención a la labor de las oficinas de transferencia de los resultados de investigación para asegurarse de que las ideas más creativas e innovadoras se mueven con fluidez desde las universidades, laboratorios o centros de investigación ${ }^{35}$. Por otro lado, los organismos públicos deberían permitir a la industria de capital riesgo adaptarse a las prácticas globales

\footnotetext{
${ }^{35}$ Entre los factores que han influido en el éxito de los programas de capital riesgo en lugares como Israel, uno de los hubs de emprendedores más activos del mundo, se encuentra un alto nivel de formación y una transferencia de resultados de investigación ágil. Israel tiene uno de los ratios de doctorados, ingenieros y científicos más altos del mundo, prestigiosas instituciones tecnológicas y médicas y una estrecha y fluida relación entre universidades, centros de tecnología militar y civil y el sector de capital riesgo de Tel Aviv. Recuérdese Acs et al. (2012) o Fraser-Sampson (2010) respecto a la función de puente que el emprendedor hace, conectando la innovación con la aplicación comercial de la misma y, por tanto, con el crecimiento económico.
} 
aceptadas de facto internacionalmente, sin encorsetarlas excesivamente en las restricciones regulatorias locales. Estas prácticas contractuales y otras variables como el régimen fiscal o el desarrollo de los mercados financieros son más relevantes a la hora de determinar el atractivo de la actividad emprendedora para los empresarios. Para Lerner también es clave educar en la cultura emprendedora a todos los niveles: a la población general para reactivar el espíritu de iniciativa empresarial; a los emprendedores sobre lo que esperan los inversores de capital riesgo y los mercados, y al sector público en los retos con los que se enfrentan tanto los emprendedores como los inversores del capital riesgo. Por último, puesto que empíricamente se ha demostrado que los proyectos de emprendedores y el capital riesgo son industrias que funcionan mejor en hubs o centros de actividad debido al intercambio de conocimientos y de best practices, es importante producir y compartir información sobre el mercado, sobre emprendedores, y sobre las inversiones de capital riesgo. En esta línea trabajan las asociaciones sectoriales de capital riesgo, tanto nacionales (ASCRI en España) como internacionales (EVCA a nivel europeo), que producen informes periódicos y recogen las estadísticas principales del sector.

\section{- Recomendaciones sobre el diseño de los programas}

Las autoridades económicas deben hilar fino al decidir el tamaño adecuado de los programas, tratando de evitar iniciativas muy pequeñas o demasiado grandes. Programas excesivamente pequeños apenas tendrán impacto en los retos que afrontan los emprendedores, pero si son demasiado grandes se corre el riesgo de que inundan el mercado local, produciéndose las patologías habituales de situaciones con demasiado capital y limitadas opciones de inversión: selección de objetivos inadecuados financiando empresas ineficientes y expulsión del mercado de inversores privados preparados y competentes.

La dotación económica y la duración del programa Fond-ICO Global ha sido parametrizada tras un exhaustivo análisis de las necesidades y desarrollo histórico del mercado doméstico de capital riesgo, que dieron como resultado la dotación de 1.200 millones durante cuatro años. Tras poco más de una año de actividad de Fond-ICO Global, se ha conseguido multiplicar casi por cinco el tamaño del sector de capital riesgo español, en términos de captación de fondos, comparando las cifras con las de los últimos seis años desde la crisis de 2008.

También es necesario evitar la tentación de sobredirigir el proceso emprendedor y las inversiones de capital riesgo. Los requisitos gubernamentales que limitan la flexibilidad tanto de inversores como de emprendedores han resultado nocivos. Es natural condicionar la ayuda pública a una cierta presencia local o inversiones adicionales en la región, pero estas condiciones deben estructurarse como unos requisitos mínimos que no ahoguen la actuación de los inversores o empresarios. 
En este sentido, en las Bases de las licitaciones de Fond-ICO Global, se establece un marco genérico de criterios de elegibilidad, habiéndose tomado voluntariamente la decisión de que sean directrices amplias para dar cabida al máximo número de candidatos posible. Además, el hecho mismo de que el programa se estructure como un fondo de fondos implica que el dinero se asigna a inversores independientes profesionales, sin que Fond-ICO interfiera en modo alguno en el desarrollo de la actividad inversora, más allá de su papel como aportante de fondos. Se especifica explícitamente que deberá siempre ser tratado en igualdad de condiciones con los otros participantes del fondo.

Por lo que se refiere a los condicionantes de inversión en la región, Fond-ICO Global exige unos volúmenes mínimos de inversión en España, puesto que uno de sus objetivos fundamentales es proporcionar vías alternativas de financiación para las empresas españolas, pero no condiciona en modo alguno el resto de inversiones del fondo receptor. Los volúmenes mínimos de inversión en compañías españolas van desde un $50 \%$ del total del fondo para venture capital y capital expansión (o dos veces la inversión de Fond-ICO Global) hasta un 90\% en el caso de los fondos de incubación. No obstante, estos requisitos mínimos de inversión local no puede considerarse que estén limitando el resto de las inversiones y tampoco condicionan el tipo de inversor. De hecho, si se revisan las cifras de las tres convocatorias cerradas hasta la fecha, puede observarse como el compromiso de inversión en empresas españolas por parte de los fondos seleccionados no representa necesariamente una proporción relevante del volumen objetivo de los fondos creados.

\section{Tabla 4}

\section{Resultados convocatorias cerradas}

\begin{tabular}{|l|c|c|l|}
\hline (Millones de euros) & $\begin{array}{c}\text { Fondo Objetivo } \\
\text { Total }\end{array}$ & \multicolumn{2}{|c|}{ Compromiso Inversión España } \\
\hline $1^{\text {a }}$ CONVOCATORIA & 685 & 660 & $\begin{array}{l}\text { Venture capital: } 148 \\
\text { Capital expansión: } 512\end{array}$ \\
\hline $2^{\text {a }}$ CONVOCATORIA & 3.785 & 665 & $\begin{array}{l}\text { Venture capital: } 142 \\
\text { Capital expansión: } 523\end{array}$ \\
\hline $3^{\text {a } \text { CONVOCATORIA }}$ & 4.125 & 669 & $\begin{array}{l}\text { Venture capital: } 67 \\
\text { Deuda: } 178 \\
\text { Capital expansión: } 424\end{array}$ \\
\hline $4^{\text {a }}$ CONVOCATORIA & 756 & 573 & $\begin{array}{l}\text { Venture capital: } 148 \\
\text { Capital expansión: } 425\end{array}$ \\
\hline & 9.351 & 2.567 & \\
\hline
\end{tabular}

Fuente: Elaboración propia con datos proporcionados por AXIS/ICO. 
Por otra parte, Lerner recuerda que es imprescindible entender la importancia de la inter-conectividad global. Tanto los emprendedores como el capital riesgo son fenómenos globales, y por mucho que el sector público quiera un impacto local, para lograr sus objetivos los agentes deben tener presencia internacional. Para ello es necesario no restringir la actividad del emprendedor a una zona determinada e involucrar a fondos extranjeros en el proceso (otras empresas y fondos locales se podrán beneficiar de su experiencia, y posiblemente suponga atraer más capital extranjero en el futuro). Esto no impide que si un inversor no nacional utiliza fondos públicos, se establezca un cierto compromiso con la región, vigilando el impacto local de la inversión y asegurándose de que la gestión del fondo, aunque localizada en otro país, va a ocuparse de la inversión realizada en la región proveedora de los fondos. En este mismo espíritu de creación de una industria global e inter-conectada, y con objeto de atraer a los fondos e inversores de mayor calidad y reputación, es interesante atraer fondos de todo tipo, que inviertan en distintas fases del ciclo de vida empresarial, y no sólo en las empresas de reciente creación.

En este sentido, las convocatorias de Fond-ICO Global, que como se acaba de mencionar se han diseñado conscientemente con criterios amplios, están abiertas tanto a candidatos nacionales como internacionales, a los cuales se les exigen los mismos requisitos. De hecho la presencia de inversores internacionales está siendo bastante significativa, tanto entre los candidatos como en los fondos seleccionados (véase la tabla 1 en el apartado anterior). Y, desde el principio, se ha ofertado apoyo no sólo para empresas de nueva creación, sino para compañías con un cierto grado de madurez que se encuentren en fases de expansión o de reestructuración, ajustando los requerimientos para cada estrategia de inversión (incubación, venture capital, capital expansión, entre otras).

Por último, Lerner reconoce la presencia de conflictos de interés y de corrupción, por lo que deben diseñarse programas públicos transparentes, con procedimientos de acceso a la financiación claros. Por tanto, las autoridades económicas responsables deberían publicitar con tiempo sus criterios de evaluación para elegir empresas o fondos y dichos criterios tendrían que ser similares a los utilizados por el sector privado. También es conveniente separar la administración de los programas de los cargos políticos públicos, y establecer mecanismos de evaluación y supervisión de los programas.

En el caso de Fond-ICO Global, al igual que ocurre con otros programas pertenecientes al ICO, se ha prestado especial atención a la transparencia durante todo el proceso de selección de los fondos. Recordemos que se trata de un programa instrumentado a través de un sistema de licitación pública, a cuyas convocatorias pueden concurrir todos aquellos que cumplan los requisitos establecidos en cada caso y que serán valorados conforme a los criterios establecidos en las bases de cada convocatoria. Dichos criterios de selección, tanto los cuantitativos como 
los cualitativos, así como su ponderación, son públicos y están accesibles desde el momento en que se lanza una convocatoria en la página web de la sociedad gestora Axis. Por último, un fondo de fondos garantiza la separación entre la autoridad pública que decide la asignación de los fondos, y los gestores privados que los van a invertir.

\section{- Recomendaciones sobre la aplicación práctica de estos programas}

Para Lerner es clave que a la hora de implementar estos programas se siga la dirección de los mercados: Uno de los mecanismos más efectivos en este sentido es coinvertir con capital privado de forma que estos matching funds marquen dónde invertir los fondos públicos ${ }^{36}$, produciéndose además un efecto multiplicador que amplifica el impacto de la ayuda estatal. El empleo de fondos privados conjuntamente con dinero público ayuda también a que las autoridades económicas logren el objetivo de evitar la competencia entre el sector público y el privado por invertir en los activos más atractivos, sin condenar a la inversión pública a financiar activos de baja calidad.

Es indudable que Fond-ICO Global es un ejemplo exitoso de cooperación público-privada en el sector del capital riesgo. Uno de los requisitos esenciales para concurrir al programa Fond-ICO Global es que el candidato acredite que cuenta con un porcentaje mínimo de inversión privada ya comprometida. Se establece además el porcentaje máximo que la inversión del ICO puede representar sobre el volumen total objetivo del fondo, debiendo ser el resto de las aportaciones de origen privado. En la mitad del horizonte temporal planteado, el programa ha logrado un compromiso mínimo de inversión en España por parte de los gestores privados superior a 2.000 millones de euros en capital expansión y por encima de 500 millones de euros en venture capital, con una inversión por parte de FondICO Global de 584 y 171 millones de euros respectivamente. Estas cifras representan un efecto multiplicador promedio que supera las 3,5 veces en los fondos de capital expansión y aproximadamente de 3 veces en los fondos de venture capital.

Es necesario, continúa Lerner, tener en cuenta que identificar las mejores iniciativas empresariales y los inversores adecuados es un proceso lento y a menudo conviene hacerlo de forma gradual, habitualmente mediante sucesivas adjudicaciones de capital a los fondos, y varias rondas de financiación a las empresas, con tiempo intermedio para recopilar feed-back y proseguir en la dirección adecuada. En general es preciso evitar la impaciencia y reconocer que los tiempos son largos. Un sector emprendedor activo tarda tiempo en construirse, no deben abandonarse programas prometedores por no ver resultados a corto plazo, lo cual no significa

${ }^{36}$ Como recuerda Lerner (2009), programas exitosos como Yozma en Israel o Seed Investment Fund en Nueva Zelanda, aun siendo muy diferentes en sus objetivos, comparten la práctica de utilizar matching funds. 
que no se deban cerrar programas que no están funcionando bien. Dicho con otras palabras, se necesitan programas públicos que sean flexibles y con un cierto grado de creatividad, para ir adaptándose a los posibles cambios y a la evolución de la actividad que se pretende financiar.

De nuevo, Fond-ICO Global ha acertado con un programa escalonado, proyectándose a lo largo de cuatro años sucesivas convocatorias de adjudicaciones de fondos. Desde septiembre de 2013, se han realizado cuatro convocatorias cuyas características se han ido adaptando a las necesidades existentes en el mercado en cada momento. En la primera y segunda convocatorias sólo se financiaban fondos de venture capital y capital expansión, mientras que en la tercera ronda también se incluyeron fondos de incubación y de deuda. Fond-ICO Global fue concebido con una vocación dinámica y flexible con el fin de que su ejecución acompañase siempre a las demandas y necesidades del mercado.

\section{- Recomendaciones sobre la supervisión, control y seguimiento posterior de los programas}

En un momento inicial, es necesaria una evaluación detallada y profesional de las iniciativas a financiar. Una vez realizada la asignación de fondos, hay que vigilar la evolución de los programas y los receptores de ayudas para comprobar que se van cumpliendo los compromisos asumidos. La continuidad del programa debe ser revisada y dependerá de si se van cumpliendo objetivos, recordando que los tiempos son largos y sin caer en el error ya mencionado de la impaciencia y el excesivo cortoplacismo. Esta revisión puede resultar más sencilla si el programa ha sido diseñado de forma que la inversión se realice de forma gradual, con posibilidad de obtener feedback intermedio sobre la evolución del mismo. También es recomendable disponer de información agregada sobre los emprendedores y sobre el capital riesgo, tal y como se mencionó en el primer grupo de recomendaciones, para poder comparar las empresas y programas que cuentan con ayuda pública de los que no la tienen. Esta supervisión y evaluación deben diseñarse cuidadosamente para optimizar las decisiones sobre el futuro del programa: debe ser posible interrumpir un programa que no cumple los objetivos previstos, o cambiar los incentivos, o incluso en casos de éxito, decidir interrumpir la ayuda pública puesto que los objetivos se han cumplido y la dinámica del mercado y la iniciativa privada ya fluyen por sí solas.

A estos efectos, Fond-ICO tiene implementadas medidas de seguimiento y supervisión, y este punto se ve reforzado por contar con asesores profesionales externos independientes, que han sido contratados por periodos de tres años. Una de las principales es el uso de una plataforma tecnológica exclusiva de los inversores privados en fondos de fondos, para contralar la información de los fondos en los que se invierte. Esta plataforma permite acceder de forma perió- 
dica a la información estandarizada que vuelcan los fondos que han recibido financiación del ICO. Por otro lado, Fond-ICO Global exige como condición un puesto en el preceptivo comité de seguimiento y supervisión en cada fondo de los que invierte. Además Fond-ICO Global se reserva el derecho a realizar todas las Due Diligences intermedias que considere necesarias solicitando información específica. Por último, las propias bases de las diferentes convocatorias establecen mecanismos de penalización caso de no cumplirse los compromisos adquiridos al recibir los fondos.

La recepción internacional del programa ha sido muy positiva, como lo demuestran los informes favorables que la Comisión Europea, el Fondo Monetario Internacional y el Banco Central Europeo han elaborado, tras las visitas que de forma regular han realizado a España para evaluar las medidas de reforma que España propuso en 2012 ${ }^{37}$. Un ejemplo ilustrativo de la buena consideración del programa fuera de nuestro país, sería la visita realizada por los responsables de Fond-ICO Global a Kazakhastan invitados por la ONU. Esta invitación tenía por objeto explicar al gobierno de este país los detalles de programas que países con una experiencia exitosa en la promoción de capital riesgo habían realizado, para lo cual únicamente se consideró oportuno llevar a representantes de Finlandia, Israel y España.

\section{CONCLUSIONES}

Las PYME y, principalmente, aquellas empresas en estados iniciales de funcionamiento son un importante motor económico, especialmente en entornos geográficos con un tejido productivo como el europeo. Teniendo en cuenta sus características específicas de riesgo y sus dificultades para acceder a financiación tradicional, el capital riesgo, que es un inversor cualificado tanto para proporcionar financiación como para asumir voluntariamente el binomio rentabilidad - riesgo específico de estas empresas jóvenes, aportando además una gestión especializada que resulta muy importante para su desarrollo, se configura como un coprotagonista insustituible en el ecosistema emprendedor para que Europa recobre la senda de crecimiento.

En el caso de Europa este enfoque es especialmente relevante, ya que se ha demostrado que a pesar de invertir en $\mathrm{I}+\mathrm{D}$ y de producir importantes resultados en innovación y desarrollo tecnológico, no se produce el esperado impacto en el crecimiento económico, lo que se ha denominado "la paradoja europea". Para solventar esta situación es necesario un estímulo al espíritu emprendedor, que se ha demostrado que es el puente entre innovación y crecimiento económico.

\footnotetext{
${ }^{37}$ Medidas propuestas para poder recibir ayuda con el fin de rescatar varias Cajas de Ahorros.
} 
Este creciente interés por la actividad de capital riesgo y su esperado efecto positivo sobre la economía en su conjunto ha producido diversas iniciativas por parte de las autoridades económicas, puesto que el sector público ha demostrado actuar como catalizador necesario en el nacimiento y desarrollo de mercados de capital riesgo. Sin embargo, el éxito de dichas políticas en la práctica ha sido variable. La doctrina ha analizado los casos de éxito y los errores más comunes realizados en el pasado al tratar de implementar este tipo de medidas, dando lugar a una serie de recomendaciones sobre la forma más adecuada de articularlas para lograr el efecto deseado. Dichas recomendaciones han sido compiladas, catalogadas y explicadas de forma detallada en la obra de Josh Lerner de 2009 Boulevard of Broken Dreams.

A la luz de estas recomendaciones, este trabajo analiza las medidas directas de apoyo al sector de capital riesgo que se han puesto en marcha recientemente en España con el programa de fondo de fondos Fond-ICO Global. Este análisis pormenorizado de las directrices comúnmente aceptadas como indicadores de éxito en el caso de los programas públicos parece arrojar un balance muy favorable para los objetivos que pretende Fond-ICO Global. Partiendo de estos parámetros parece fácil concluir que es un programa correctamente concebido y que cuenta con unos principios preestablecidos en cuanto al desarrollo del mismo, acordes con las prácticas y recomendaciones identificadas en el mercado como clave del éxito.

\section{BIBLIOGRAFÍA}

ACS, Z. J., AUDRETSCH, D. B., BRAUNERHJELM, P. y CARLSSON, B. (2012), "Growth and entrepreneurship", Small Business Economics, vol. 39, núm. 2, pp. 289-300.

AMIT, R., GLOSTEN, L. y MULLER, E. (1990), "Entrepreneurial Ability, Venture Investments and Risk Sharing", Management Science, vol. 36, núm. 10, pp. 1232-1245.

ASCRI (2014), Informe de actividad de Capital Riesgo en España, Asociación Española de Entidades de Capital-Riesgo.

ASCRI (2012), Informe 2012 sobre impacto económico y social del capital riesgo, Asociación Española de Entidades de Capital-Riesgo.

BALBOA RAMÓN, M. y MARTÍ PELLÓN, J. (2011), "Sensibilidad de la oferta de capital riesgo a cambios en el marco regulatorio", Revista de Economía Aplicada, vol. XIX, núm. 55, pp. 61-94.

BERNSTEIN, S., LERNER, J., SØRENSEN, M. y STRÖMBERG, P. (2010), "Private Equity and Industry Performance", National Bureau of Economic Research, NBER Working Paper 15632. Disponible en: http://www.nber. org/papers/w15632 (última consulta: 10 de diciembre de 2014). 
BLACK, B. S. y GILSON, R. J. (1998), "Venture Capital and the Structure of Capital Markets", Journal of Financial Economics, vol. 47, pp. 243-277.

BOE (2014), Ley 22/2014, de 12 de noviembre, por la que se regulan las entidades de capital-riesgo, otras entidades de inversión colectiva de tipo cerrado y las sociedades gestoras de entidades de inversión colectiva de tipo cerrado, y por la que se modifica la Ley 35/2003, de 4 de noviembre, de Instituciones de Inversión Colectiva. Boletín Oficial del Estado, 13 de noviembre de 2014, núm. 275, pp. 93215-93320.

BULEVSKA, A. (2014), "Can Economic Growth Be Enhanced by Venture Capital Employment?", Journal of Sustainable Development, vol. 5, núm. 10, pp. 50-69.

CALLEJA CRESPO, D. (2013), "Los emprendedores, motor de la economía europea", Newsletter ICO, núm. 6, septiembre.

CARLSSON, B., ACS, Z. J., AUDRETSCH, D. B. y BRAUNERHJELM, P. (2009), "Knowledge Creation, Entrepreneurship, and Economic Growth: A Historical Review”, Industrial $\mathcal{E}$ Corporate Change, vol. 18, núm. 6, pp. 1193-1229.

DA RIN, M., NICODAMO, G. y SEMBENELLI, A. (2005), "Public Policy and the Creation of Active Venture Capital Markets", European Central Bank-Working Paper Series, núm. 430, enero.

DEMARIA, C. (2013), Introduction to Private Equity: Venture, Growth, LBO E Turn-Around Capital, 2nd Edition, John Wiley \& Sons, Chichester, United Kingdom.

DUSHNITSKY, G. y SHAPIRA, Z. (2010), "Entrepreneurial Finance Meets Organizational Reality: Comparing Investment Practices and Performance of Corporate and Independent Venture Capitalists", Strategic Management Journal, vol. 31, núm. 9, pp. 990-1017.

EUROPEAN CENTRAL BANK (2014), Survey on the access to finance of Small and Medium-sized Enterprises in the euro area: April 2014-September 2014, noviembre.

EUROPEAN COMMISSION (2014), Annual Report on European SMEs 2013/2014 - A Partial and Fragile Recovery, julio. Disponible en: http:// ec.europa.eu/enterprise/policies/sme/facts-figures-analysis/performancereview/files/supporting-documents/2014/annual-report-smes-2014_en.pdf

EVCA (2014), 2013 European Private Equity Activity: Statistics on Fundraising, Investments $\mathcal{E}$ Divestments, European Private Equity and Venture Capital Association, mayo.

FRONTIER-ECONOMICS/EVCA (2013), Exploring the impact of private equity on economic growth in Europe, European Private Equity and Venture Capital Association, mayo. Londres, United Kingdom. 
FRASER-SAMPSON, G. (2010), Private Equity as an Asset Class, John Wiley $\&$ Sons, Chichester, United Kingdom.

GEFAELL, J. (2014), Entrevista recogida en Newsletter ICO, num 7, marzo.

GOMPERS, P. A. (1995), "Optimal Investment, Monitoring and the Staging of Venture Capital", The Journal of Finance, vol. 50, num 5, diciembre, pp. 1461-1489

GOMPERS, P. A. y LERNER, J. (1998), "What Drives Venture Capital Fundraising?", Brookings Papers on Economic Activity, Microeconomics, julio, pp. 149-192.

GOMPERS, P. A. y LERNER, J. (2001), "The Venture Capital Revolution", Journal of Economic Perspectives, vol. 15, núm. 2, primavera, pp. 145-168.

HELLMANN, T. y PURI, M. (2000), "The Interaction Between Product Market and Financing Strategy: The Role of Venture Capital", The Review of Financial Studies, vol. 13, núm. 4, invierno, pp. 959-984

HELLMANN, T. y PURI, M. (2002), "Venture Capital and the Professionalization of Start-Up Firms: Empirical Evidence", The Journal of Finance, vol. LVII, núm. 1, febrero, pp. 169-197

HSU, D. H. (2004), "What do Entrepreneurs Pay for Venture Capital Affiliation?, The Journal of Finance, vol. LIX, núm. 4, agosto, pp. 1805-1844.

JENG, L. A. y WELLS, P. C. (2000), "The Determinants of Venture Capital Funding: Evidence Across Countries", Journal of Corporate Finance, vol. 6, núm. 3, septiembre, pp. 241-289.

KORTUM, S. y LERNER, J. (2000), "Assessing the contribution of venture capital to innovation”, RAND journal of Economics, vol. 31, núm. 4, invierno, pp. 674-692.

LERNER, J. (2009), Boulevard of Broken Dreams: Why Public Efforts to Boost Entrepreneurship and Venture Capital Have Failed, and What to Do About It. Ed. Princeton University Press, Princeton, New Jersey.

LERNER, J. y SAHLMAN, W. (2012), "Reviving Entrepreneurship", Harvard Business Review, marzo, pp. 116-119.

LERNER, J. y TAG, J. (2013), "Institutions and Venture Capital", Industrial and Corporate Change, vol.22, núm.1, pp. 153-182.

MICHELACCI, C. (2003), "Low Returns in R\&D Due to the Lack of Entrepreneurial Skills”, Economic Journal, núm. 113, enero, pp. 207-225.

OCDE (2014), Entrepreneurship at a Glance 2014, OECD Publishing. Disponible en http://dx.doi.org/10.1787/entrepreneur_aag-2014-en

OCDE (2013), Financing SMEs and Entrepreneurs 2013: An OECD Scoreboard, OECD Publishing.

PARK, H. D. y STEENSMA, H. K. (2012), "When Does Corporate Venture Capital Add Value for New Ventures?", Strategic Management Journal, vol. 33, núm. 1, pp. 1-22. 
PELLY, R. (2013), "Aumento de capital para emprendedores en tiempos difíciles”, Newsletter ICO, núm. 6, septiembre.

SAHLMAN, W. A. (1990), "The Structure and Governance of Venture Capital Organizations", Journal of Financial Economics, vol. 27, núm. 2, pp. 473-521.

SAMILA, S. y SORENSON, O. (2010), "Venture Capital as a Catalyst to Commercialization", Research Policy, vol. 39, núm.10, diciembre, pp. 1348-1360.

STRÖMBERG, P. (2009), The Economic and Social Impact of Private Equity in Europe: Summary of Research Findings, septiembre. Disponible en http:// www.fvca.fi/files/30/EVCA_DOC_RP_ECONIMPACT_0909.pdf

VENCKUVIENE, V. y SNIESKA, V. (2014), "Government Sponsored Venture Capital Funds and their Relation to Innovation in Lithuanian SMEs", Economics E⿱ Management, vol. 19, núm. 1, pp. 54-62. 